\title{
Printed paper-based arrays as substrates for biofilm formation
}

\author{
Anni Määttänen ${ }^{*}$, Adyary Fallarero ${ }^{2}$, Janni Kujala ${ }^{2}$, Petri Ihalainen ${ }^{1}$, Pia Vuorela ${ }^{3}$ and Jouko Peltonen ${ }^{1}$
}

\begin{abstract}
The suitability of paper-based arrays for biofilm formation studies by Staphylococcus aureus is demonstrated. Laboratory-coated papers with different physicochemical properties were used as substrates. The array platform was fabricated by patterning the coated papers with vinyl-substituted polydimethylsiloxane (PDMS) -based ink. The affinity of bacteria onto the flexographically printed hydrophobic and smooth PDMS film was very low whereas bacterial adhesion and biofilm formation occurred preferentially on the unprinted areas, i.e. in the reaction arrays. The concentration of the attached bacteria was quantified by determining the viable colony forming unit $\left(\mathrm{CFU} / \mathrm{cm}^{2}\right)$ numbers. The distribution and the extent of surface coverage of the biofilms were determined by atomic force microscopy. In static conditions, the highest bacterial concentration and most highly organized biofilms were observed on substrates with high polarity. On a rough paper surface with low polarity, the biofilm formation was most hindered. Biofilms were effectively removed from a polar substrate upon exposure to (+)-dehydroabietic acid, an anti-biofilm compound.
\end{abstract}

Keywords: Biofilm formation; Staphylococcus aureus; Polarity; Surface roughness; AFM; PDMS

\section{Introduction}

Bacteria can switch between two different life styles: single cells floating in a liquid medium (planktonic mode) and sessile cells (biofilm mode). Biofilms are surface-attached bacterial life forms which can be described as wellorganized communities of cells that are surrounded by a self-produced layer of an extracellular polymeric substance (EPS). Biofilms cause serious threat to human health. They are responsible for a significant number of chronic antibiotic-resistant infections (Donlan and Costerton 2002). Their chemoresistance has been attributed to various factors. One mechanism is related to the presence of the EPS, which acts as a protective barrier against biocides and toxins and it sequesters nutrients from the environment, thus being an essential part of the strategy of bacteria for persistence under extreme, unfavourable conditions (McDougald et al. 2011). Other mechanisms include slower growth rate and the presence of resistant subpopulations (persister cells) (Proctor et al. 1994; Fux et al. 2005; Anderson and O'Toole 2008). It has also been shown that biofilms are more tolerant to environmental

\footnotetext{
* Correspondence: anni.maattanen@abo.fi

${ }^{1}$ Laboratory of Physical Chemistry, Center of Excellence for Functional

Materials, Abo Akademi University, Turku, Finland

Full list of author information is available at the end of the article
}

bacteriophages and phagocytic amoebae than planktonic bacteria (Higashi and Sullam 2006).

Staphylococcus aureus is a Gram-positive bacterium regarded as an etiologic agent of a wide range of diseases associated with significant morbidity and mortality and is a leading cause of nosocomial infections (Jabra-Rizk et al. 2006). In this study S. aureus was selected as a model biofilm-forming organism given its profound association with serious biofilm-mediated pathologies. For instance, it has been established that Staphylococcus spp. biofilms account for more than a half of infections associated with prosthetic devices (Fluckiger et al. 2005). In addition, $S$. aureus colonize diabetic, pressure and venous ulcers as well as burn wounds which can result in non-healing infection and may even lead to death. Additionally, $S$. aureus biofilms are involved in the first stage of cystic fibrosis (CF), as well as in chronic otitis media and osteomyelitis (Lindsay and von Holy 2006). Unfortunately, all the antibiotics that are currently in use today have been developed to act against dividing phase planktonic bacteria and there is a pressing need for compounds that can selectively act on staphylococcal biofilms (Elliot et al. 1982; Landini et al. 2010; Worthington et al. 2012; Blackledge et al. 2013; Ausbacher et al. 2014).

\section{Springer}


Substrate properties are important for biofilm growth since bacteria generally prefer to grow on available surfaces rather than in the surrounding aqueous phase (Katsikogianni and Missirlis 2004). Physicochemical surface properties such as roughness and surface energetics, together with the properties of the suspending medium (e.g. $\mathrm{pH}$, surface tension and/or presence of proteins), have been shown to have an influence on the strength and direction (decrease/increase) of microbial adhesion and subsequent biofilm formation (Absolom et al. 1983; Fletcher and Pringle 1985; Litzler et al. 2007; Chung et al. 2007; Zmantar et al. 2011; Mosier and Cady 2011; Nill et al. 2011; Singh et al. 2012). In addition, electrostatic interactions (surface charge) and viscoelastic properties (elastic modulus) of the substrate have been shown to influence the bacterial adherence (Brady 1999; Rosenhahn et al. 2009).

Paper is a sustainable and recyclable material, and its physicochemical properties (topography, roughness, stiffness, surface energy, polarity, porosity and pore geometry) can be modified quite conveniently by various coating materials and methods and surface treatments (Ihalainen et al. 2012). Furthermore, the surface of paper can be functionalized by printing of not only graphical inks but also e.g. functional polymers and biomaterials (Siegel et al. 2009; Määttänen et al. 2011; Tian and Shen 2011; Li et al. 2012; Wang et al. 2012). By patterning paper for instance with a PDMS-based ink, printable paper-based alternatives for conventional plastic microtiter plates can be fabricated (Määttänen et al. 2011; Juvonen et al. 2013). The role of the low surface energy PDMS film can be to confine the liquids or, to direct biomaterial adhesion and growth of e.g. human ARPE-19 cells on the unprinted (PDMS-free) areas as recently demonstrated (Juvonen et al. 2013).

The goals of this work were to study the effect of certain physicochemical properties of different paper-based substrates on bacterial biofilm growth in static conditions, as well as to demonstrate the use of the printed platform in the investigation of biofilm susceptibility to an antimicrobial agent. The array was constructed through flexographic printing of a patterned PDMS layer on four different types of coated paper substrates with characteristic surface topography, roughness and surface energetics. The changes in bacterial biofilm morphology were followed by high resolution microscopic techniques. The susceptibility tests were conducted using (+)-dehydroabietic acid. The effects of this potent anti-biofilm molecule against $S$. aureus have been recently reported (Fallarero et al. 2013) and they were verified here by topographical means.

\section{Materials and methods Substrates}

Four different types of reverse gravure coated papers including substrates coated with two latex blends (coded:
Latex 1, Latex 2) and substrates coated with two mineral pigments (coded: Kaolin and PCC (precipitated calcium carbonate)) were fabricated, characterized and used for the biofilm formation studies. A 96-well polystyrene microplate and a PDMS-printed paper substrate were used as reference substrates. Additional file 1: Table S1 summarizes the raw materials used in the substrates.

The detailed fabrication procedures and properties of the multilayer pigment-coated paper substrates have been described in earlier publications (Bollström et al. 2009, 2010; Määttänen et al. 2010).

The aqueous latex blends consisted of film-forming (low glass transition temperature $\left(\mathrm{T}_{\mathrm{g}}\right)$ ) and non-film-forming (high $\mathrm{T}_{\mathrm{g}}$ ) components. The hard high- $\mathrm{T}_{\mathrm{g}}$ latex (plastic pigment) particles (size $100-200 \mathrm{~nm}$ ) provide blocking resistance, mechanical strength and integrity to the film, while the soft (low $\mathrm{T}_{\mathrm{g}}$ ) latex particles act as a film-forming component (Schuler et al. 2000; Ihalainen et al. 2007, 2010). All the paper substrates were dried by using an IR lamp and calendered before use, pigment-based substrates at a nip pressure and temperature of 50 bars and $70^{\circ} \mathrm{C}$ and latex-based substrates at 70 bars and $35^{\circ} \mathrm{C}$, respectively. The latex coatings were washed with purified water and absolute ethanol and further IR cured for $1 \mathrm{~min}$ in order to thermally modify the topography to gain a bimodal structure with a large surface area.

The printed array platforms (Figure $1 \mathrm{a}$ and $\mathrm{b}$ ) for biofilm formation experiments were fabricated by flexographic printing of a single layer of the PDMS-based hydrophobic, translucent and solvent-free ink on the studied paper substrates by using pre-designed flexographic printing plates with well diameters of $2 \mathrm{~mm}$ or $5 \mathrm{~mm}$ (a photograph shown in Additional file 1: Figure S1). A more detailed description of the procedure is given elsewhere (Määttänen et al. 2011). In addition, the back side of the substrates was covered with the PDMS ink in order to direct the biofilm formation into the spherical nonprinted areas. The arrays were disinfected with ethanol and sterile water prior to use in the biofilm studies and surface characterization.

\section{Atomic force microscopy (AFM)}

An NTEGRA Prima (NT-MDT, Russia) atomic force microscope (AFM) was used for analyzing the topography of the substrates and the biofilms. The microscope was placed on an active vibration isolation table (TS-150, Table Stable Ltd., Switzerland), which was further placed on a stone table to eliminate external vibrational noise. Topography imaging was carried out in intermittentcontact mode under ambient conditions (relative humidity $(\mathrm{RH})=30 \pm 10 \%$, room temperature $(\mathrm{RT})=26 \pm$ $2^{\circ} \mathrm{C}$ ) using uncoated rectangular silicon cantilevers (MikroMasch, model DP16/GP/AlBS (typical resonance frequency: $170 \mathrm{kHz}$, typical spring constant: 40 


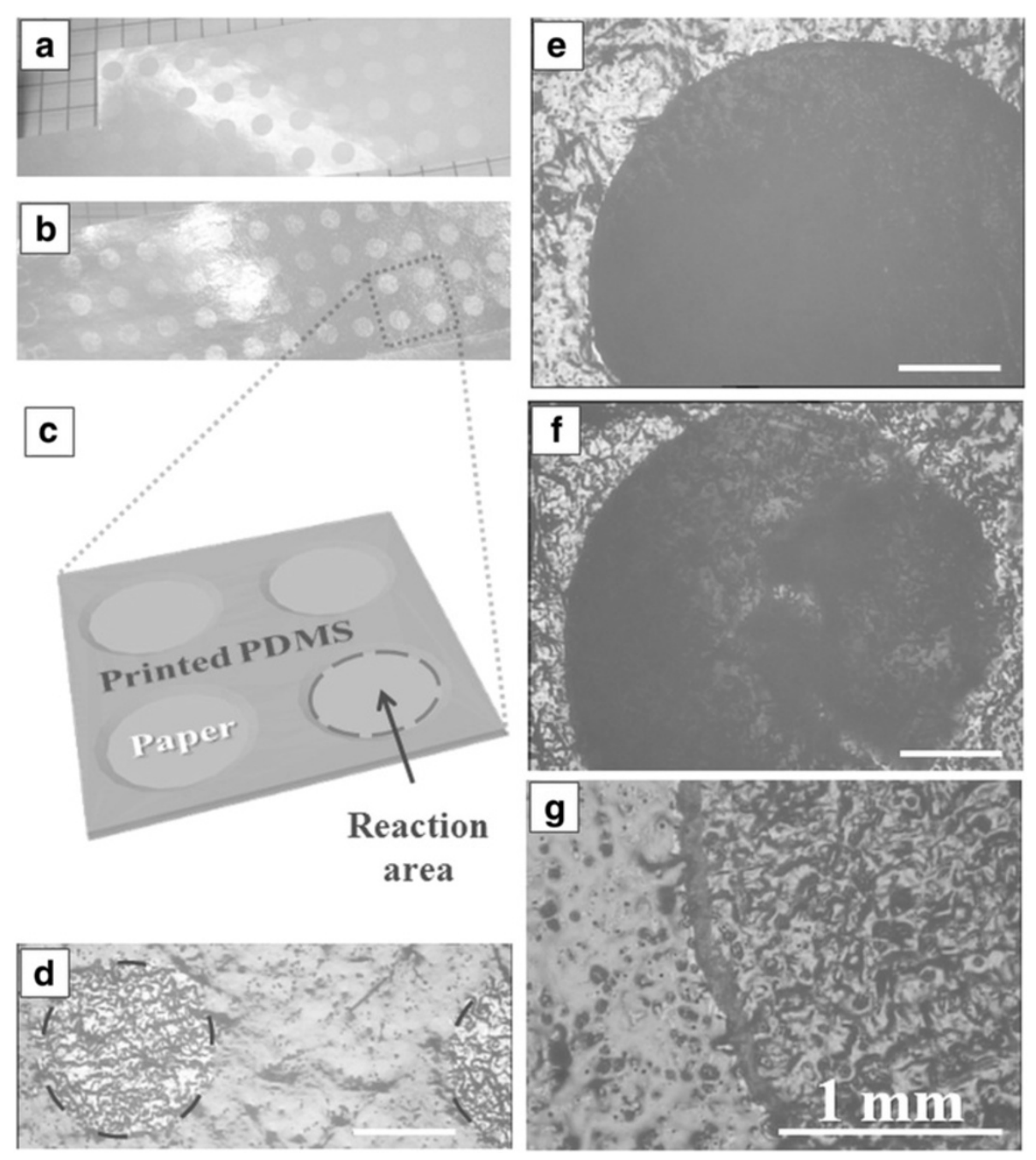

Figure 1 Paper-based platforms for biofilm studies. A digital photograph of the arrays fabricated on a) Kaolin coated paper and b) latex coated paper. A schematic illustration of the reaction array platform c). Optical micrograph of an unexposed reaction area on Latex 2 substrate d). Optical micrograph of the reaction array fabricated on Latex 2 after exposure to e) S. aureus (18 h), f) S. aureus for 5 min followed by incubation in TSB for 18 hours, and g) S. aureus (18 h) followed by exposure to K2 (24 h). Diameters of the reaction areas are $2 \mathrm{~mm}$ in d, and $5 \mathrm{~mm}$ in others. The scale bar is $1 \mathrm{~mm}$.

$\mathrm{N} / \mathrm{m}$ ) and NT-MDT, models NSG10 (resonance frequency: $240 \mathrm{kHz}$, spring constant: $11.8 \mathrm{~N} / \mathrm{m})$ and NSG30 (resonance frequency: $240 \mathrm{kHz}$, spring constant: $40 \mathrm{~N} / \mathrm{m})$ ). The images were recorded in the repulsive regime using a damping ratio of $0.6-0.7$ and a scan speed of $0.2-0.4 \mathrm{~Hz}$. The AFM images were processed and analyzed with the Scanning Probe Image Processor software (SPIP ${ }^{\mathrm{m}}$, Image Metrology, Denmark) and the following roughness parameters were calculated for describing the surfaces: root mean square (RMS) roughness $\left(\mathrm{S}_{\mathrm{q}}\right)$, root mean square gradient $\left(S_{\mathrm{dq}}\right)$ and the surface area ratio $\left(\mathrm{S}_{\mathrm{dr}}\right) . \mathrm{S}_{\mathrm{q}}$ expresses the standard deviation of the height values within the image, $S_{\mathrm{dq}}$ the root mean square average of the local surface slopes within the sampling area and $S_{\mathrm{dr}}$ the increment of the interfacial surface area relative to the area of the projected (flat) $x-y$ plane (Stout et al. 1993). Also the height difference between the highest peak and the lowest valley ( $\mathrm{S}_{\mathrm{z}}$ or Z-range) is reported.

\section{Contact angle and surface energy determination}

A CAM 200 contact angle goniometer (KSV Instruments Ltd) was used for the measurements of static contact angles of water, diiodomethane (DIM) and ethylene glycol (EG) on the different substrates in ambient conditions $\left(\mathrm{RH}=15 \pm 5 \%, \mathrm{RT}=24 \pm 1^{\circ} \mathrm{C}\right)$. Small droplets $(1-2 \mu \mathrm{L})$ were gently deposited on the samples and the contact angles were recorded as a function of time using the software supplied with the instrument. Apparent contact angle values $\theta_{\mathrm{a}}$ (average of three measurements) were obtained at a point of time where the drop diameter, contact angle 
and volume had stabilized to a constant level. The OwensWendt method, where the total surface energy $\left(\gamma_{\mathrm{s}}\right)$ is determined as the sum of the polar $\left(\gamma_{s}^{\mathrm{p}}\right)$ and dispersive $\left(\gamma_{s}^{\mathrm{d}}\right)$ components was used for the surface energy determination (Owens and Wendt 1969). The $\theta_{\mathrm{a}}$ values (apparent values) were corrected for roughness by the Wenzel's equation $\cos \theta_{\mathrm{a}}=r \cos \theta_{\mathrm{v}}$ where $\theta_{\mathrm{r}}$ is the contact angle for a smooth surface, and $r$ is a roughness factor (Wenzel 1936). The $r$ value was calculated by using the roughness parameter $\mathrm{S}_{\mathrm{dr}}$ (Table 1); $r=1+\mathrm{S}_{\mathrm{dr}} / 100$ (Peltonen et al. 2004). The surface energy values were determined by using the $\theta_{\mathrm{r}}$ values. The values of surface tension components suggested by van Oss et al. were used for the probe liquids (van Oss et al. 1987, 1988).

\section{Biofilm studies}

\section{Biofilm formation}

Staphylococcus aureus (ATCC 25923) was used as a model for biofilm-forming bacteria in all the experiments. Typically, biofilms are prepared in vitro using 96-well microplates made of polystyrene (Nunclon $\Delta$ surface, Nunc, Roskilde, Denmark). Therefore, this plastic surface was used as a reference substrate to compare the biofilm formation with those observed for the paper substrates. Bacterial cultivation and biofilm forming experiments on 96-well microplates were conducted as previously described (Sandberg et al. 2008). Briefly, bacteria were cultured in $30 \mathrm{~g} / \mathrm{L}$ Tryptic Soy Broth (TSB) (Fluka Biochemika, Switzerland) under aerobic conditions at $37^{\circ} \mathrm{C}$ for 4 hours and $200 \mathrm{rpm}$ to reach exponential growth, up to a concentration of $10^{8} \mathrm{CFU} / \mathrm{mL}$. To promote biofilm formation, a bacterial suspension $\left(10^{6} \mathrm{CFU} / \mathrm{mL}, 200 \mu \mathrm{L} /\right.$ well, in TSB) was added into 96well microplates and they were incubated for $18 \mathrm{~h}$ under aerobic conditions $\left(37^{\circ} \mathrm{C}, 200 \mathrm{rpm}\right)$ as described earlier (Sandberg et al. 2008). Paper-based substrates were used in a pattern of 4 well diameters ( $5 \mathrm{~mm}$ each). Biofilm formation in the paper substrates was monitored using a modified microtiter well plate assay. The substrates were placed in 6-well microplates, into which suspensions of exponentially grown bacteria $\left(10^{6} \mathrm{CFU} / \mathrm{mL}, 5 \mathrm{~mL} /\right.$ well, in TSB) were added and biofilms were similarly allowed to be formed at $37^{\circ} \mathrm{C}, 200 \mathrm{rpm}$ for $18 \mathrm{~h}$. The total substrate

Table 1 Determined surface roughness parameters for the studied substrates

\begin{tabular}{lllll}
\hline Surface & $\mathbf{S}_{\mathbf{z}}[\mathbf{n m}]$ & $\mathbf{S}_{\mathbf{q}}[\mathbf{n m}]$ & $\mathbf{S}_{\mathbf{d q}}[\mathbf{1 / n m}]$ & $\mathbf{S}_{\mathbf{d r}}[\%]$ \\
\hline Latex 1 & 314.7 & 9.0 & 0.18 & 1.6 \\
Latex 2 & 218.6 & 13.0 & 0.47 & 10.0 \\
Kaolin & 431.5 & 49.6 & 0.74 & 25.0 \\
PCC & 584.8 & 75.6 & 0.88 & 42.0 \\
PS (96-well) & 34.8 & 4.8 & 0.07 & 0.3 \\
PDMS & 15.5 & 1.5 & 0.04 & 0.1 \\
\hline
\end{tabular}

area where biofilms could be formed in the printed substrates was calculated to be $0.784 \mathrm{~cm}^{2}$. At the end of the incubation period, the suspensions were removed from the plates and the substrates were transferred to sterile 6-well plates for visualization with AFM. Parallel samples were rinsed in sterile water (by immersion for a few seconds) and biofilms were scraped off the substrates in $100 \mu \mathrm{L}$ TSB using sterile plastic sticks and rinsed with additional $100 \mu \mathrm{L}$ of TSB. To disperse the bacterial aggregates, samples were immersed in a high power ultrasonic bath (Bandelin Sonorex Digitec) using an in-house built-in device that allowed them to be in full contact with water without touching the bottom surface of the sonicator. The sonication time was kept short ( $5 \mathrm{~min}, 35 \mathrm{kHz}$ ) and performed at RT. The disaggregated biofilms were serially diluted, spread onto Tryptic Soy Agar (TSA) plates and incubated at $37^{\circ} \mathrm{C}$ overnight. The morphology of the resulting bacterial colonies was inspected and confirmed to be S. aureus. The inclusion of paper controls that were inoculated only with media, allowed the exclusion of potential contamination.

Viable bacterial cell densities were quantified and expressed as $\mathrm{CFU} / \mathrm{cm}^{2}$. The differences between the area distributions where biofilms were formed in the printed substrates and the microtiter well plates were taken into account, since in the wells biofilms were also formed on the sides of the wells, not only on the bottom.

\section{Initial adhesion studies}

To study the impact of the initial adhesion on the substrates, two of them (Latex 2 and PCC) were exposed to $S$. aureus suspensions, as described in Biofilm formation section. Instead of $18 \mathrm{~h}$, the suspensions were added to the substrates only for 5 minutes to allow only the occurrence of initial attachment. After that time, suspensions were removed and fresh TSB was added, and the samples were incubated for 18 hours. AFM images of the samples were performed right after finishing this procedure.

\section{Biofilm maintenance on the substrates}

Comparative studies between sample Latex 2 and the 96-well polystyrene microplates were performed. Biofilms were formed as described earlier in Biofilm formation section. At the end of the incubation period (18 h), TSB was removed and samples were stored without culture media at $+4^{\circ} \mathrm{C}$ for 1 or 2 weeks. At the end of the storage period, the presence of biofilms was confirmed by AFM. Also, the density of viable biofilm bacteria was measured by scraping bacteria off from the surface. 


\section{Effect of an anti-biofilm compound}

After the $18 \mathrm{~h}$ biofilm formation period, $20 \mu \mathrm{L}$ of (+)-dehydroabietic acid (coded K2, at a concentration of $400 \mu \mathrm{M}$ ) was added on top of the biofilms formed on the Latex 2 surface. Samples were then kept for 24 hours under aerobic conditions $\left(37^{\circ} \mathrm{C}, 200 \mathrm{rpm}\right)$. AFM images were taken at the end of the incubation period with $\mathrm{K} 2$.

\section{Results}

\section{Characterization of the substrates}

Figure 2 shows typical AFM topographical images $(10 \mu \mathrm{m} \times$ $10 \mu \mathrm{m})$ of the studied substrates. Figure 3 depicts line profiles over the respective substrates showing their distinct morphologies with a gradually increasing surface peakedness and roughness. The determined roughness parameters for each substrate are listed in Table 1 . The smoothest surface, PDMS, appeared featureless with clearly the smallest $S_{\mathrm{z}}, \mathrm{S}_{\mathrm{q}}, \mathrm{S}_{\mathrm{dq}}$ and $\mathrm{S}_{\mathrm{dr}}$ values. The polystyrene 96 microwell was found to have the next smoothest surface, however, showing a surface texture generated by the molding process. The heat-treated latex-coated surfaces (Latex 1, Figure 2a and Latex 2, Figure 2b) consisted of very flat top areas with grooves and recesses abruptly interrupting the otherwise rather smooth surface. This resulted in a quite structured column-like surface morphology, especially in case of Latex 2. The Kaolin and PCC pigment-based coating surfaces consisted of randomly oriented pigment particles with their characteristic morphologies (platy-like Kaolin and rod-like PCC). The roughness values show that these surfaces were clearly the roughest.

Table 2 presents the roughness corrected contact angles $\left(\theta_{\mathrm{r}}\right)$ as well as the polar $\left(\gamma_{s}^{\mathbf{p}}\right)$ and dispersive $\left(\gamma_{s}^{\mathbf{d}}\right)$ surface energy components and the total surface energy $\left(\gamma_{\mathrm{s}}\right)$ values for each substrate. Kaolin and Latex 2 coated samples were found to have the smallest water contact angles and highest polarities. On the contrary, the contact angles of the probe liquids on the PDMS surface are all over $90^{\circ}$, demonstrating the hydrophobic and nonwetting nature of the material.

\section{Characterization of the biofilm growth}

Figures 1a and b show two typical digital photographs of the paper-based arrays fabricated by printing a translucent PDMS pattern on a pigment coated paper and on a latex coated paper. Figure 1c shows a schematic illustration of the reaction array platform. As an example, Figure 1d shows an optical micrograph of the reaction areas (diameter $2 \mathrm{~mm}$ ) on Latex 2 sample before exposure to the bacterial culture. Figures $1 \mathrm{e}$ and $\mathrm{f}$ show that culturing changed the optical contrast inside the reaction area from light to dark. When the Latex 2 sample that was first exposed to $S$. aureus for $18 \mathrm{~h}$ was treated with an antibiofilm compound, the contrast changed back to light
(Figure 1g). For Latex 1 and PCC similar clear contrast change was not observed (Additional file 1: Figure S2). AFM measurements were carried out to study in more detail the bacterial attachment and biofilm growth on the arrays fabricated on the different substrates (Figure 4).

\section{Bacterial exposure to the different substrates (18 $h)$ and biofilm formation}

The arrays fabricated on the different substrates were exposed to $S$. aureus for $18 \mathrm{~h}$. The total concentration of biofilm in the reaction areas was quantified by scraping the attached cells off and plating them in TSA (Table 3). Latex 2 and Kaolin surfaces were the most prone to the formation of $S$. aureus biofilm with the highest recovered counts $\left(\mathrm{CFU} / \mathrm{cm}^{2}\right)$ of viable biofilms. The theoretical $\mathrm{CFU} / \mathrm{cm}^{2}$ value for a monolayer of hexagonally closepacked $S$. aureus cells is $1.14 \times 10^{8}$ assuming that the width of a single cell is $1 \mu \mathrm{m}$ (Additional file 1: Figure S3). On Kaolin and Latex 2 samples the $\mathrm{CFU} / \mathrm{cm}^{2}$ value was higher than $1.14 \times 10^{8}$ indicating at least partial multilayer coverage. The multilayer formation is further confirmed by comparing the height of an individual cell $(\sim 560 \mathrm{~nm}$, Additional file 1: Figure S3) to the $S_{z}$ value $(1168 \mathrm{~nm})$ of the AFM image (Figure 4b). The AFM topographs show that adsorbed bacterial cells formed a relatively close-packed and fully covering biofilm on both samples (Figure $4 \mathrm{~b}$ and $\mathrm{c}$ ). This confirms that on Latex 2 the dark area in the optical micrograph corresponded to the bacterial biofilm and it supports the suitability of applying optical micrographic technique for visualizing biofilm growth on this type of non-conventional substrates.

Compared to Latex 2 and Kaolin samples, less biofilm was formed on the other studied substrates (Figures 4a, $\mathrm{d}-\mathrm{f})$. This is in accordance with the lower $\mathrm{CFU} / \mathrm{cm}^{2}$ values (Table 3). On Latex 1 sample the optical micrographs (Additional file 1: Figure S2) show unevenly distributed patches with a darker contrast. The AFM measurements confirmed that the dark areas corresponded to a biofilm (Figure 4a i) whereas the light areas contained no biofilm (Figure 4a ii). On the other hand, the surface of PCC sample contained both areas where no biofilm had formed (Figure 4f) and areas where loosely packed S. aureus capsules with a height of 400-700 nm partially covered the pigment coating (Additional file 1: Figure S3). Finally, very sporadically distributed bacterial cells were observed on the printed PDMS surfaces (Figure 4f).

\section{Short bacterial exposure to the different substrates (5 mins) and further biofilm formation}

Differences in the initial attachment of bacteria to the substrates were studied by using PCC (the substrate less prone to biofilm formation) and Latex 2 (one of the substrates more prone to biofilm formation). Figures $1 \mathrm{f}$ and 5 a show that rapid bacterial attachment took place on 
a

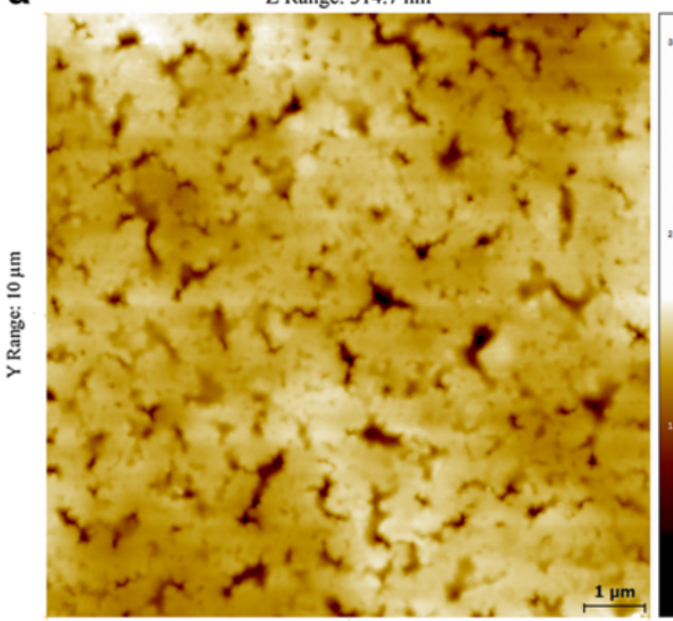

$X$ Range: $10 \mu \mathrm{m}$

c

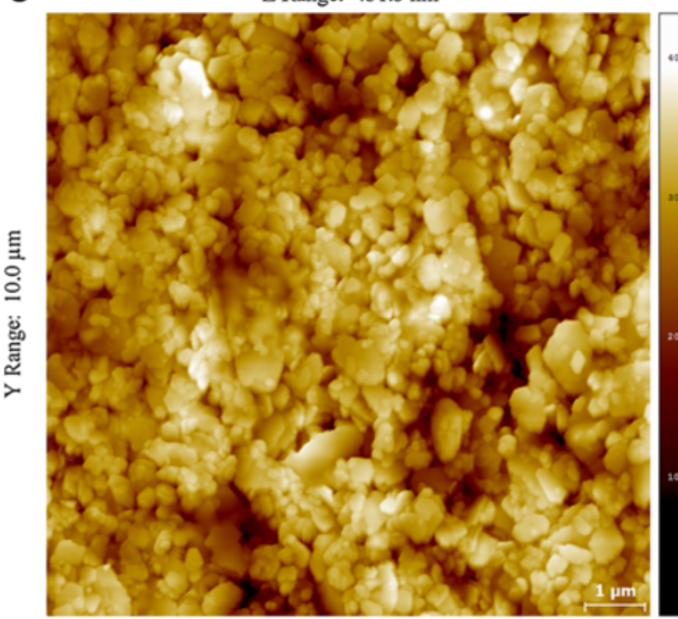

e

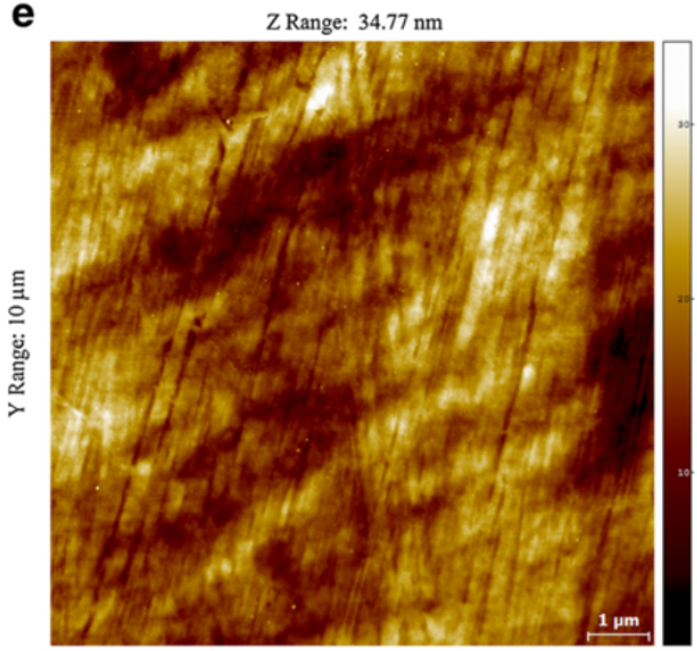

$\mathrm{X}$ Range: $10 \mu \mathrm{m}$

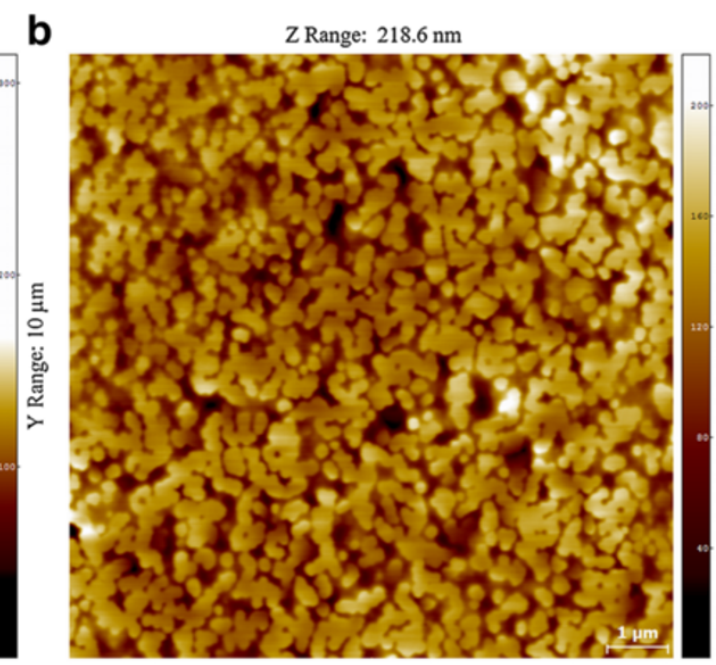

$\mathrm{X}$ Range: $10 \mu \mathrm{m}$

d

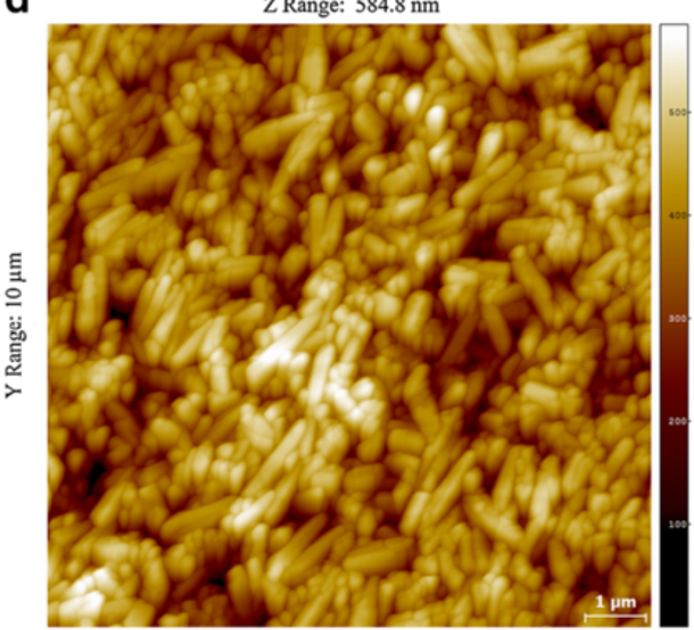

$\mathrm{X}$ Range: $10 \mu \mathrm{m}$

f

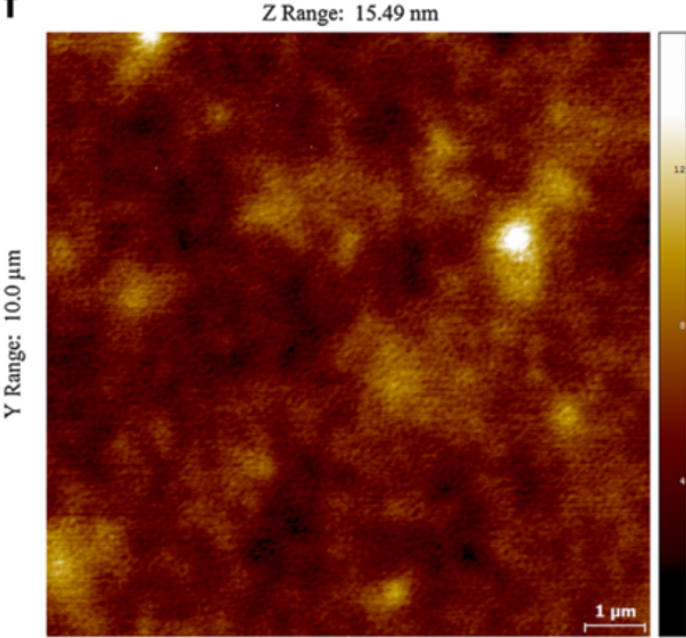

$\mathrm{X}$ Range: $10.0 \mu \mathrm{m}$

Figure 2 AFM characterization of the substrates. Topographical images $(10 \mu \mathrm{m} \times 10 \mu \mathrm{m})$ of the paper substrates with coating a) Latex 1, b) Latex 2, c) Kaolin and d) PCC. Also included are topographs of the e) polystyrene 96-well microplate and $\mathbf{f}$ ) the printed PDMS surface. The scale bar in each image is $1 \mu \mathrm{m}$. 


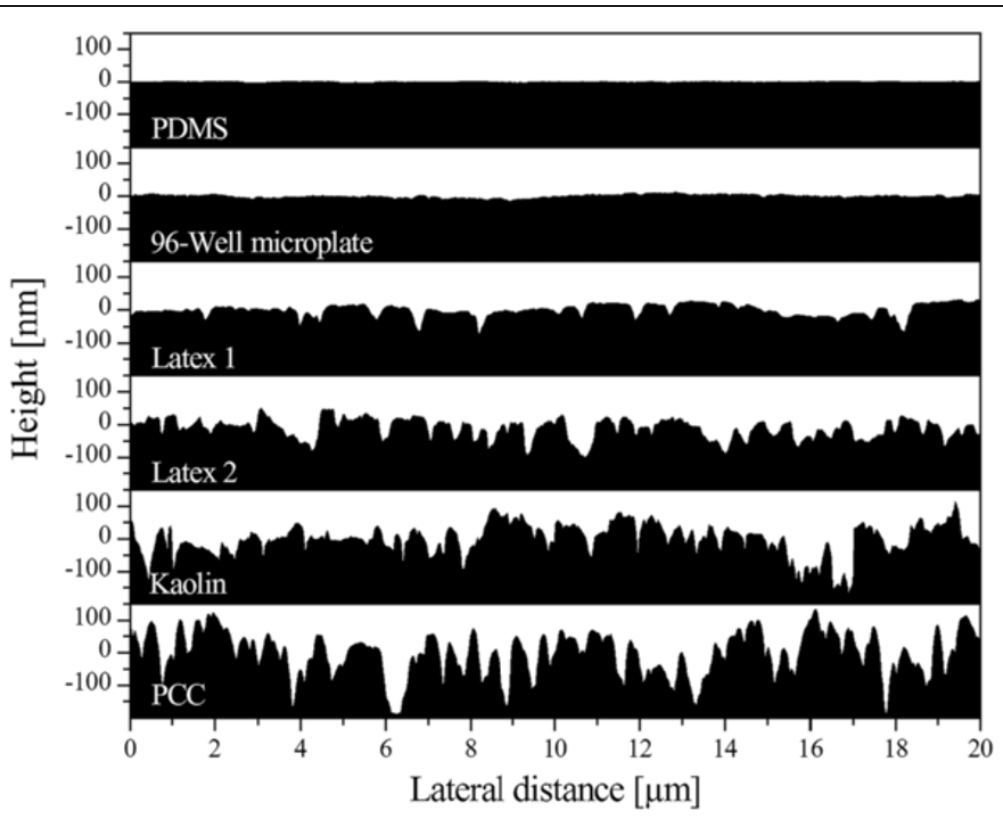

Figure 3 AFM line profiles of the studied substrates. Representative height profiles of the studied substrates showing the gradually increasing roughness.

Latex 2, and these initially attached cells were enough to allow biofilm formation during 18 hours. On the contrary to Latex 2, no indication of bacterial attachment was observed on the PCC sample as the rod-like pigment particles were still clearly visible after exposure to $S$. aureus solution (Figure 5b).

\section{Maintenance of biofilms on a selected substrate}

The stability of the $S$. aureus biofilm formed on Latex 2 sample was followed by storing freshly prepared biofilms for 1 and 2 weeks at $+4^{\circ} \mathrm{C}$. The influence of storage time on the density of the viable biofilm cells is shown in Table 3. The evolution of topography of the biofilm during storage was followed by AFM. Additional file 1: Figure S4 shows AFM topographs after 0, 1 and 2 weeks storage. Corresponding height profiles are shown in Additional file 1: Figure S5.

\section{The effect of an anti-biofilm compound on the biofilm}

The effect of the application of (+)-dehydroabietic acid (K2) on the pre-formed $S$. aureus biofilm (Figure 6a) was studied on the Latex 2 sample, as this substrate was found particularly prone to biofilm formation. From Figure $1 \mathrm{~g}$ we already saw that the influence of K2 was significant as the dark optical contrast characteristic of the biofilm had nearly totally disappeared, indicating biofilm desorption. Only a narrow dark-appearing stripe was left at the perimeter of the reaction area. Detailed AFM characterization (Figure 6b) confirmed that the dark stripe corresponded to the remaining biofilm (the left hand side of Figure $6 \mathrm{~b})$. The average thickness of the biofilm (<500 nm, see the line profile in Figure $6 \mathrm{~b})$ was somewhat reduced from the thickness of a fully functional biofilm and approximately $150 \mathrm{~nm}$ deep and 400-600 nm wide craters had been formed.

\section{Discussion}

Influence of substrate properties on biofilm growth Roughness and topography

Previous studies have shown that initial bacterial attachment is directly dependent on the surface roughness of the substrate as increasing roughness usually leads to an increase in surface area accessible to bacteria (Kawai et al. 2000; Carlén et al. 2001). The PCC sample has clearly the highest $S_{\mathrm{q}}$ and $\mathrm{S}_{\mathrm{dr}}$ values amongst the studied substrates (Table 1), and purely from the roughness perspective would be expected to have the highest initial bacterial attachment. However, the CFU counts and AFM measurements revealed that the $S$. aureus cells adhered better on the Latex 2 sample compared to the rougher PCC sample even after only 5 minutes of exposure.

While high roughness has been said to be beneficial for the initial adherence of bacteria (Kawai et al. 2000; Carlén et al. 2001), the size and shape of the grooves, scratches, depressions and other topographical features are also important. Bacteria have been shown to preferentially adhere to irregularities that conform to their size due to the increased bacteria-surface contact area (Katsikogianni and Missirlis 2004). Protruding topographical features on the other hand have been shown to decrease the biofilm 
Table 2 Wetting and surface energy characterization

\begin{tabular}{|c|c|c|c|c|c|c|}
\hline \multirow[t]{2}{*}{ Surface } & \multicolumn{3}{|l|}{$\theta_{r}\left[^{\circ}\right]$} & \multicolumn{3}{|c|}{ Surface energy $[\mathrm{mN} / \mathrm{m}]$} \\
\hline & Water & DIM & EG & $V_{s}^{p}$ & $\gamma_{s}^{d}$ & $\gamma_{\mathrm{s}}$ \\
\hline Latex 1 & $84 \pm 1$ & $52 \pm 1$ & $73 \pm 1$ & 3.4 & 27.8 & 31.2 \\
\hline Latex 2 & $74 \pm 3$ & $47 \pm 2$ & $59 \pm 2$ & 6.6 & 31.3 & 37.9 \\
\hline Kaolin & $64 \pm 2$ & $50 \pm 1$ & $48 \pm 1$ & 12.2 & 29.9 & 42.1 \\
\hline PCC & $92 \pm 3$ & $52 \pm 1$ & $52 \pm 2$ & 1.4 & 34.7 & 36.1 \\
\hline PS (96-well) & $80 \pm 1^{b}$ & $37 \pm 2^{b}$ & $53 \pm 2^{b}$ & 3.2 & 38.2 & 41.4 \\
\hline $\mathrm{PDMS}^{\mathrm{a}}$ & $114 \pm 1^{b}$ & $92 \pm 2^{b}$ & $96 \pm 1^{\mathrm{b}}$ & 0.6 & 11.7 & 12.3 \\
\hline
\end{tabular}

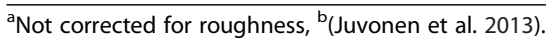

growth kinetics and enhance the aggregation of bacteria. Chung et al. for instance found out that an engineered PDMS surface with microtopographic features hindered the $S$. aureus biofilm formation compared to smooth PDMS surfaces (Chung et al. 2007). The protruded topographical features act as physical barriers to inhibit the expansion of small clusters of bacteria residing in surface cavities, physically disrupting further colonization and subsequent biofilm formation (Chung et al. 2007). Previously, the biofilm growth of $S$. aureus has been shown to be independent on surface morphology when the protruding height features were more than one order of

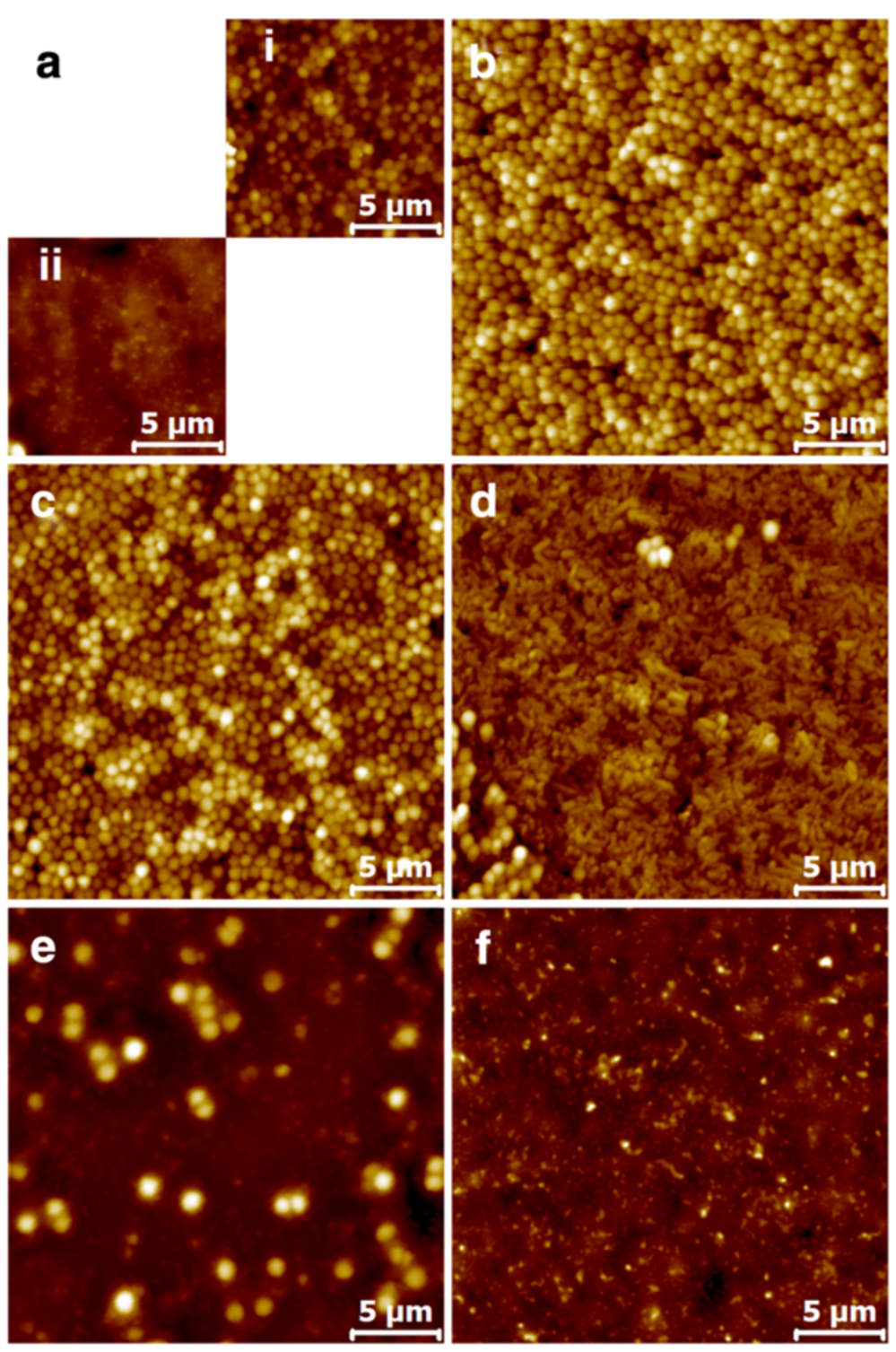

Figure 4 AFM characterization of the substrates exposed to $\mathbf{S}$. aureus for $\mathbf{1 8} \mathbf{h}$. Topographical images $(25 \mu \mathrm{m} \times 25 \mu \mathrm{m})$ of a) Latex 1 , b) Latex 2, c) Kaolin, d) PCC, e) PS, and f) PDMS exposed to S. aureus for $18 \mathrm{~h}$. Z-ranges are: a i) $768 \mathrm{~nm}$, ii) $469 \mathrm{~nm}$, b) $1168 \mathrm{~nm}$, c) $749 \mathrm{~nm}$, d) $907 \mathrm{~nm}, \mathbf{e )} 780 \mathrm{~nm}$ and f) $158 \mathrm{~nm}$. The scale bar in each image is $5 \mu \mathrm{m}$. 
Table 3 Quantification of the bacterial biofilms attached to the substrates

\begin{tabular}{|c|c|c|c|}
\hline \multirow[t]{2}{*}{ Surface } & \multicolumn{3}{|l|}{ Recovered biofilms } \\
\hline & $\begin{array}{l}\text { Right after the } 18 \mathrm{~h} \\
\text { incubation period } \\
{\left[\mathrm{CFU} / \mathrm{cm}^{2}\right]}\end{array}$ & $\begin{array}{l}\text { After } 1 \text { week } \\
\text { storage in }+ \\
4^{\circ} \mathrm{C}\left[\mathrm{CFU} / \mathrm{cm}^{2}\right] \\
\end{array}$ & $\begin{array}{l}\text { After } 2 \text { weeks } \\
\text { storage in }+ \\
4^{\circ} \mathrm{C}\left[\mathrm{CFU} / \mathrm{cm}^{2}\right]\end{array}$ \\
\hline Latex 1 & $1.8 \times 10^{7}$ & & \\
\hline Latex 2 & $2.5 \times 10^{8}$ & $4.3 \times 10^{7}$ & $4.6 \times 10^{6}$ \\
\hline Kaolin & $3.1 \times 10^{8}$ & & \\
\hline PCC & $1.4 \times 10^{7}$ & & \\
\hline PS (96-well) & $5.0 \times 10^{7}$ & $3.5 \times 10^{7}$ & $3.6 \times 10^{6}$ \\
\hline PDMS & $1.0 \times 10^{6}$ & & \\
\hline
\end{tabular}

magnitude lower than the size of the bacterial cells (Litzler et al. 2007). Comparing the size of a bacterial capsule (height $\sim 560 \mathrm{~nm}$ and width $\sim 1 \mu \mathrm{m}$, Additional file 1: Figure S3) and the $S_{z}$ values of the substrates, the morphology of PDMS and PS (96-well plate) substrates should not hinder the biofilm growth. The $S_{z}$ values of the other substrates are considerably higher. Despite this, areas covered by a biofilm were seen on Latex 2 and Kaolin substrates, small local biofilm islands even on Latex 1. The reason might be that the spatial distance (spacing) between the protruding features is small compared to the size of the $S$. aureus cells. Therefore, from the perspective of the $S$. aureus cell capsules e.g. the Kaolin surface might appear not that much different from the Latex 2 surface. The PCC sample was the only coated paper substrate where the bacteria never formed a continuous fully covering biofilm. Since the surface energy, polarity and CFU's of the PCC and Latex 1 were very similar, the main remaining factor differentiating these two samples was roughness, i.e. the protruding topographical features obviously must play a role on the biofilm formation.

\section{Surface energy}

The initial adhesion of $S$. aureus to polymer substrates has been shown to depend on both the surface energy of the substrate and the surface tension of the suspending liquid medium (Absolom et al. 1983). When the surface tension of the liquid medium was near that of water $(72.8 \mathrm{mN} / \mathrm{m})$ the adhesion increased linearly with decreasing surface energy of the substrate (Absolom et al. 1983). However, when the surface tension of the suspending liquid was lower than that of $S$. aureus $(\sim 69 \mathrm{mN} / \mathrm{m})$ (Absolom et al. 1983), the dependence was the opposite. With equal surface tension values no correlation was observed. Considering that the growth medium used here (TSB) had a lower surface tension $(\sim 44 \mathrm{mN} / \mathrm{m})$ (Keller 1998) compared to $S$. aureus, it is expected that the substrates with the highest surface energies, i.e. PS (96-well), Kaolin and Latex 2 yield the largest initial bacterial adhesion. The results of the short term exposure test carried out for Latex 2 and PCC substrates were in agreement with this. However, no clear correlation between the total surface energy and CFU could be established (Tables 2 and 3). This indicates that the $S$. aureus biofilm growth was apparently independent on total surface energy at the conditions used in this work. The only significant observation is that clearly the lowest biofilm growth was seen on PDMS which has the lowest surface energy. The PDMS film features low surface energy due to the flexible polymer backbone of the polydimethylsiloxane and vinyl group terminated silicone polymers that readily adapt the lowest surface energy configuration (Duel and Owen 1983; Candries et al. 2001; Juvonen et al. 2013). PDMS elastomers have also gained attention in foul release systems on ship hulls (Brady 2000), as suitable polymer matrixes for incorporation of antimicrobials and thereby as materials that are highly resistant to microbial colonization (Pudleiner et al. 2006). It has been previously shown

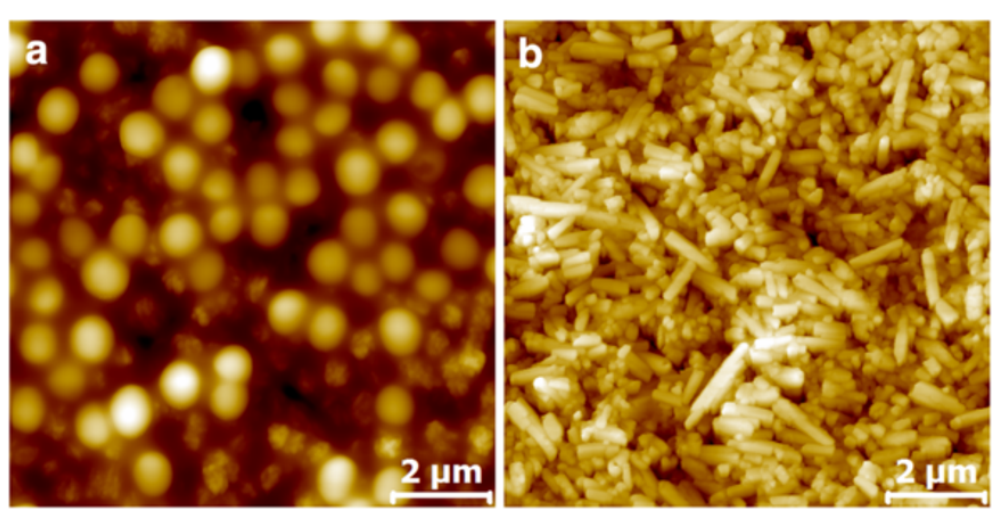

Figure 5 AFM characterization of Latex 2 and PCC substrates exposed to $\mathbf{S}$. aureus for $\mathbf{5}$ minutes. Topographical images (10 $\mu \mathrm{m} \times 10 \mu \mathrm{m})$ of a) Latex 2 and b) PCC sample exposed to S. aureus for 5 min followed by exposure to TSB for 18 h. The Z ranges are a) 799 nm and $\mathbf{b}) 1004$ $\mathrm{nm}$ and scale bars $2 \mu \mathrm{m}$. 

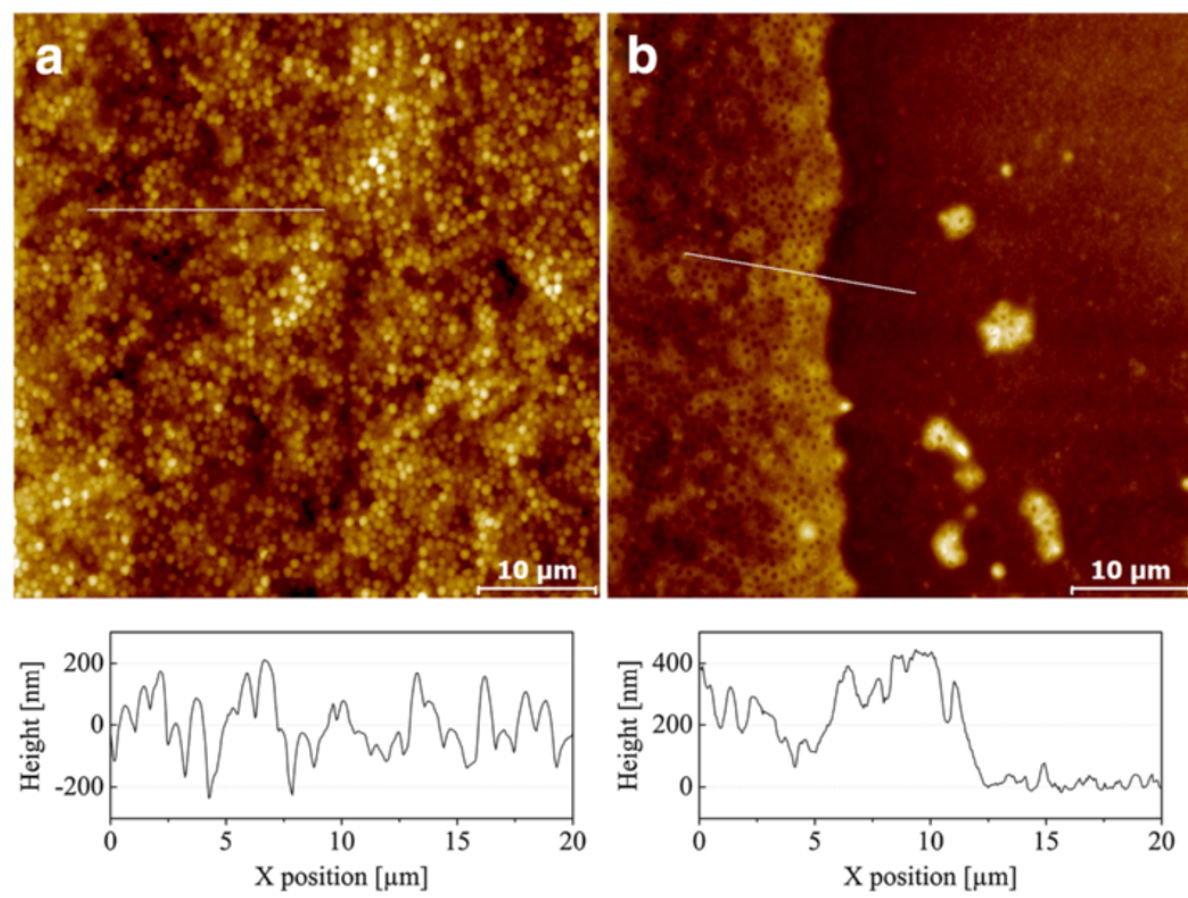

Figure 6 Influence of the antibiofilm compound on the biofilm. AFM topographical images (50 $\mu \mathrm{m} \times 50 \mu \mathrm{m})$ of the a) untreated S. aureus biofilm on Latex 2 and $\mathbf{b}$ ) preformed biofilm on Latex 2 treated with (+)-dehydroabietic acid (K2). The line profiles are shown below the corresponding topographs.

that biofilm growth of $S$. aureus was independent on the surface energy when the values were between 31 and $41 \mathrm{mN} / \mathrm{m}$ (Litzler et al. 2007). Here, the surface energies of the studies substrates (excluding PDMS) fall approximately between this range and hence might explain the poor correlation between the total surface energy and the CFU value. On the other hand, the CFU value shows a much clearer tendency to increase with increasing polarity (polar component value, $\gamma_{\mathrm{s}}^{\mathrm{p}}$ ) of the surface (Figure 7).
It has been observed that contact angle of water, which is closely related to the polarity of the substrate, relates better to bacterial film growth in aqueous systems compared to the total surface energy values (Fletcher and Pringle 1985). The amount of bacteria attached to the surface has been shown to increase with decreasing contact angle within the range from 110 to ca. 70-80 (Fletcher and Pringle 1985). Here, a similar trend was observed. While hydrophilic interactions increase with

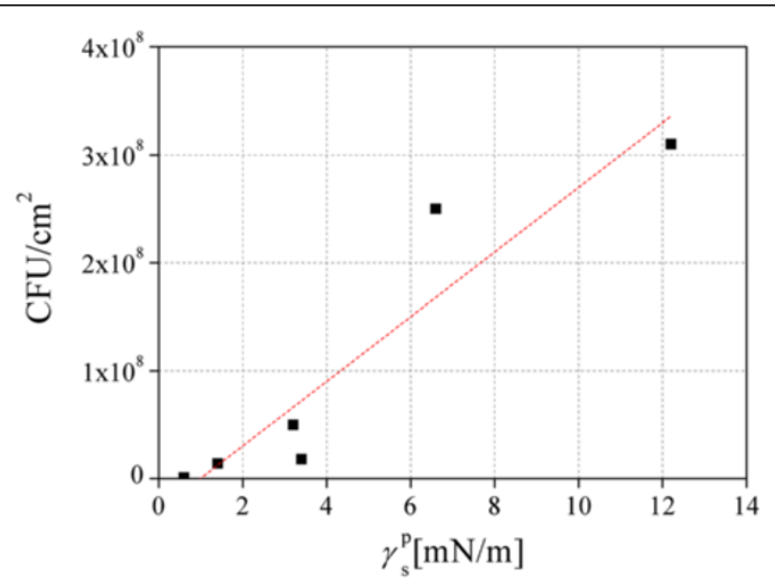

Figure 7 The trend between the $\mathrm{CFU} / \mathrm{cm}^{2}$ and polarity. Bacterial concentration values plotted as a function of the polar surface energy component. The line is not a theoretical fit but has been included in order to demonstrate the trend. 
increasing polarity, similar dependence is shown here between the polarity and the viable colony counts.

\section{Biofilm formation on paper-based arrays}

$S$. aureus biofilms were more prone to form on the polar substrates as was clearly seen for Latex 2 . Although the substrates used in this work were paper-based materials, it is important to note that they are furnished with a barrier layer which quite effectively prevents the absorption of water and inhibits the soaking effect commonly observed with the conventional paper grades, such as copy paper or filter paper. Soaking could have been one potential explanation for the higher bacterial attachment, but it is not the case with these substrates. In addition, the pigment coated papers have very small average pore size $(50-100 \mathrm{~nm})$ and thus the individual bacterial cells are not expected to fit into the pores and absorb deep into the coating. Finally, the hydrophobic PDMS further prevents the water soaking effect.

After a very short period of time (5 mins) S. aureus became effectively attached to Latex 2 and the cells present were enough to allow biofilm formation during 18 hours (as indicated by AFM results). The long-term stability and possible destruction of the biofilms on Latex 2 was studied by following the amount of biofilm during storage. The amount of bacteria on the surface dropped by approximately one order of magnitude per week during sample storage, being still on a level of $10^{7}$ after one week storage (Table 3). This amount of bacteria is similar to that observed for the 96-well PS microplates which is still enough for conducting anti-biofilm studies. Similar decreasing $\mathrm{CFU} / \mathrm{cm}^{2}$ values as a function of time have been observed also on other substrates, e.g. polymer films with S. aureus and other bacteria (Aviv et al. 2007). To offer a proof-of-concept for the suitability of this substrate for anti-biofilm studies, Latex 2 was exposed to (+)-dehydroabietic acid, a molecule that has been recently shown to display high potency and efficacy against $S$. aureus biofilms, in vitro (Fallarero et al. 2013). It has been previously demonstrated (by fluorescence microscopy) that this compound significantly kills biofilm bacteria attached to 96-well microplates, causing more than 4-log reduction of the viable biofilm density, at $400 \mu \mathrm{M}$ upon 24 hours exposure. The results obtained in this study using AFM imaging are in agreement with these previous findings. One advantage of using the planar paperbased samples is the fact that sample preparation and AFM analysis becomes more straightforward compared to the 96-well plate bottoms. Other future improvements and potential advantages related to the use of the planar and flexible paper-based platforms include e.g. the possibility to print potential antimicrobial agents on the wells prior to the biofilm formation experiments. Such experiments are currently underway. This concept is preliminary demonstrated in Additional file 1: Figure S6 which shows AFM images of $S$. aureus biofilms on Latex 2 pre-treated with printed penicillin.

\section{Additional file}

\begin{abstract}
Additional file 1: Table S1. The main components of the paper coatings and the reference samples. Figure S1. A digital photograph showing the flexographic printing plates. Figure S2. High magnification optical micrographs of the dry and empty a) Latex 1 and b) PCC substrates before exposure to bacterial suspension and c, d) after the $18 \mathrm{~h}$ biofilm formation period. Figure S3. AFM topographical image $(20 \mu \mathrm{m} \times 10 \mu \mathrm{m})$ of the PCC + S. aureus sample and corresponding height profiles. Figure S4. AFM topographical images $(20 \mu \mathrm{m} \times 20 \mu \mathrm{m})$ of the formed biofilms stored at $4^{\circ} \mathrm{C}$ for a) 0, b) 1 and c) 2 weeks. Figure S5. AFM height profiles of the $S$. aureus biofilms stored for 0,1 and 2 weeks. Figure S6. Preliminary antibiotic printing trials were carried out with two penicillin concentrations: $0.1 \mu \mathrm{M}$ $(0.0334 \mu \mathrm{g} / \mathrm{mL})$ and $1 \mu \mathrm{M}(0.334 \mu \mathrm{g} / \mathrm{mL})$. The AFM topographs $(20 \mu \mathrm{m} \times 20$ $\mu \mathrm{m})$ and the corresponding line profiles show that a much denser and thicker bacterial biofilm formed on the Latex 2 sample that was pre-treated with the lower penicillin concentration (a) compared to the higher concentration (b).
\end{abstract}

Competing interests

The authors declare that they have no competing interests.

\section{Authors' contributions}

AM participated in the design and coordination of the study, carried out AFM and CA measurements and contributed in the drafting of the manuscript. JK performed bacterial adhesion experiments. AF, PI, PV and JP participated in the design and coordination of the study and contributed in the drafting of the manuscript. All authors read and approved the final manuscript.

\section{Acknowledgements}

Technical contributions of Malena Skogman and Suvi Manner are greatly appreciated. Natalja Genina and Niklas Sandler are acknowledged for printing of penicillin. Laboratory of Paper Coating and Converting, Åbo Akademi University is acknowledged for preparing the pigment coated paper substrates. Funding from the Academy of Finland through the National Center of Excellence programme (FunMat CoE) is acknowledged (A.M., P. I., J. P.). Funding from Drug Discovery and Chemical Biology (Biocenter Finland) and Academy of Finland (decisions 128870, 264064 and 272266) are acknowledged (A.F., P.V.)

\section{Author details}

'Laboratory of Physical Chemistry, Center of Excellence for Functional Materials, Abo Akademi University, Turku, Finland. ${ }^{2}$ Pharmaceutical Sciences, Department of Biosciences, Abo Akademi University, Turku, Finland. ${ }^{3}$ Division of Pharmaceutical Biology, Faculty of Pharmacy, University of Helsinki, Helsinki, Finland.

Received: 18 February 2014 Accepted: 25 February 2014 Published online: 06 June 2014

\section{References}

Absolom DR, Lamberti FV, Policova Z, Zingg W, van Oss CJ, Neumann AW (1983) Surface thermodynamics of bacterial adhesion. Appl Environ Microbiol 46:90-97

Anderson GG, OToole GA (2008) Innate and induced resistance mechanisms of bacterial biofilms. Curr Top Microbiol Immunol 322:85-105

Ausbacher D, Fallarero A, Kujala J, Määttänen A, Peltonen J, Strøm MB, Vuorela PM (2014) Staphylococcus aureus biofilm susceptibility to small and potent $\beta^{2,2}$-amino acid derivatives. Biofouling 30:81-93

Aviv M, Berdicevsky I, Zilberman M (2007) Gentamicin-loaded bioresorbable films for prevention of bacterial infections associated with orthopedic implants. J Biomed Mater Res A 83:10-19

Blackledge MS, Worthington RJ, Melander C (2013) Biologically inspired strategies for combating bacterial biofilms. Curr Opin Pharmacol 13:699-706 
Bollström R, Määttänen A, Tobjörk D, Ihalainen P, Kaihovirta N, Österbacka R, Peltonen J, Toivakka M (2009) A multilayer coated fiber-based substrate suitable for printed functionality. Org Electron 10:1020-1023

Bollström R, Määttänen A, Ihalainen P, Peltonen J, Toivakka M (2010) Method for creating a substrate for printed or coated functionality, substrate, functional device and its use. PCT/FI2010/050056, WO 2010/086511.

Brady RF Jr (1999) Properties which influence marine fouling resistance in polymers containing silicon and fluorine. Prog Org Coat 35:31-35

Brady RF (2000) Clean hulls without poisons: devising and testing nontoxic marine coatings. J Coat Technol 72:45-56

Candries M, Anderson CD, Atlar M (2001) Foul release systems and drag. Proceedings of the PCE 2001 Conference, Antwerp, pp 273-286

Carlén A, Nikdel K, Wennerberg A, Holmberg K, Olsson J (2001) Surface characteristics and in vitro biofilm formation on glass ionomer and composite resin. Biomaterials 22:481-487

Chung KK, Schumacher JF, Sampson EM, Burne RA, Antonelli PJ, Brennan AB (2007) Impact of engineered surface microtopography on biofilm formation of Staphylococcus aureus. Biointerphases 2:89-94

Donlan RM, Costerton JW (2002) Biofilms: survival mechanisms of clinically relevant microorganisms. Clin Microbiol Rev 15:167-193

Duel LA, Owen MJ (1983) ESCA studies of silicone release coatings. J Adhes 16:49-59

Elliott GR, Peterson PK, Verbrugh HA, Freiberg MR, Hoidal JR, Quie PG (1982) Influence of subinhibitory concentrations of penicillin, cephalothin, and clindamycin on staphylococcus aureus growth in human phagocytic cells. Antimicrob Agents Chemother 22:781-784

Fallarero A, Skogman M, Kujala J, Rajaratnam M, Moreira VM, Yli-Kauhaluoma J, Vuorela P (2013) (+)-Dehydroabietic acid, an abietane-type diterpene, inhibits Staphylococcus aureus biofilms in vitro. Int J Mol Sci 14:12054-12072

Fletcher M, Pringle JH (1985) The effect of surface free energy and medium surface tension on bacterial attachment to solid surfaces. J Colloid Interface Sci 104:5-14

Fluckiger U, Ulrich M, Steinhuber A, Döring G, Mack D, Landmann R, Goerke C, Wolz C (2005) Biofilm formation, icaADBC transcription, and polysaccharide intercellular adhesin synthesis by staphylococci in a device-related infection model. Infect Immun 73:1811-1819

Fux CA, Costerton JW, Stewart PS, Stoodley P (2005) Survival strategies of infectious biofilms. Trends Microbiol 13:34-40

Higashi J, Sullam P (2006) Staphylococcus aureus biofilms. In: Pace J, Rupp M, Finch R (eds) Biofilms, Infection, and Antimicrobial Therapy. CRC Press, Florida, pp 81-108

Ihalainen P, Backfolk K, Sirviö P, Peltonen J (2007) Thermal analysis and topographical characterization of latex films by scanning probe microscopy. J Appl Phys 101:043505

Ihalainen P, Backfolk K, Sirviö P, Peltonen J (2010) Topographical, chemical, thermal and electrostatic properties of latex films. Colloids Surf A Physicochem Eng Asp 354:320-330

Ihalainen P, Määttänen A, Järnström J, Tobjörk D, Österbacka R, Peltonen J (2012) Influence of surface properties of coated papers on printed electronics. Ind Eng Chem Res 51:6025-6036

Jabra-Rizk MA, Meiller TF, James CE, Shirtliff ME (2006) Effect of farnesol on Staphylococcus aureus biofilm formation and antimicrobial susceptibility. Antimicrob Agents Ch 50:1463-1469

Juvonen H, Määttänen A, Laurén IP, Urtti A, Yliperttula M, Peltonen J (2013) Biocompatibility of printed paper-based arrays for 2-D cell cultures. Acta Biomater 9:6704-6710

Katsikogianni M, Missirlis YF (2004) Concise review of mechanisms of bacterial adhesion to biomaterials and of techniques used in estimating bacteriamaterial interactions. Eur Cell Mater 8:37-57

Kawai K, Urano M, Ebisu S (2000) Effect of Surface Roughness of porcelain on adhesion of bacteria and their synthesizing glucans. J Prosthet Dent 83:664-667

Keller SW (1998) Determination of the Leak Size Critical to Package Sterility Maintenance. Virginia Polytechnic Institute and State University, Blacksburg, Virginia

Landini P, Antoniani D, Burgess J, Nijland R (2010) Molecular mechanisms of compounds affecting bacterial biofilm formation and dispersal. Appl Microbiol Biot 86:813-823

Li M, Tian J, Al-Tamimi M, Shen W (2012) Paper-based blood typing device that reports patient's blood type 'in writing'. Angew Chem Int Ed 51:5497-5501

Lindsay D, von Holy A (2006) Bacterial biofilms within the clinical setting: what healthcare professionals should know. J Hosp Infect 64:313-325

Litzler P-Y, Benard L, Barbier-Frebourg N, Vilain S, Jouenne T, Beucher E, Bunel C, Lemeland J-F, Bessou J-P (2007) Biofilm formation on pyrolytic carbon heart valves: influence of surface free energy, roughness, and bacterial species. J Thorac Cardiovasc Surg 134:1025-1032

Määttänen A, Ihalainen P, Bollström R, Toivakka M, Peltonen J (2010) Wetting and print quality study of an inkjet-printed poly(3-hexylthiophene) on pigment coated papers. Colloids Surf A 367:76-84

Määttänen A, Fors D, Wang S, Valtakari D, Ihalainen P, Peltonen J (2011) Paper-based planar reaction arrays for frinted diagnostics. Sens Actuators B 160:1404-1412

McDougald D, Rice SA, Barraud N, Steinberg PD, Kjelleberg S (2011) Should we stay or should we go: mechanisms and ecological consequences for biofilm dispersal. Nat Rev Microbiol 10:39-50

Mosier AP, Cady NC (2011) Analysis of bacterial surface interactions using microfluidic systems. Sci Prog 94:431-450

Nill P, Kern DP, Goehring N, Peschel A (2011) Influence of surface patterning on bacterial growth behavior. J Vac Sci Technol B Microelectron Nanometer Struct 29:06FA03

Owens DK, Wendt RC (1969) Estimation of the surface free energy of polymers. J Appl Polym Sci 13:1741-1747

Peltonen J, Järn M, Areva S, Linden M, Rosenholm JB (2004) Topographical parameters for specifying a three-dimensional surface. Langmuir 20:9428-9431

Proctor RA, Balwit JM, Vesga O (1994) Variant subpopulations of Staphylococcus aureus as cause of persistent and recurrent infections. Infect Agents Dis 3:302-312

Pudleiner H, Dujardin R, Albers R (2006) Active ingredient-containing silicone elastomers. US 11/718,587: PCT/EP2005/011365

Rosenhahn A, Finlay JA, Pettit ME, Ward A, Wirges W, Gerhard R, Callow ME, Grunze M, Callow JA (2009) Zeta potential of motile spores of the green alga Ulva linza and the influence of electrostatic interactions on spore settlement and adhesion strength. Biointerphases 4:7-11

Sandberg M, Määttänen A, Peltonen J, Vuorela PM, Fallarero A (2008) Automating a 96-well microtitre plate model for Staphylococcus aureus biofilms: an approach to screening of natural antimicrobial compounds. Int J Antimicrob Agents 32:233-240

Schuler B, Baumstark R, Kirsch S, Pfau A, Sandor M, Zosel A (2000) Structure and properties of multiphase particles and their impact on the performance of architectural coatings. Prog Org Coat 40:139-150

Siegel AC, Phillips ST, Wiley BJ, Whitesides GM (2009) Thin, lightweight, foldable thermochromic displays on paper. Lab Chip 9:2775-2781

Singh AV, Vyas V, Salve TS, Cortelli D, Dellasega D, Podestà A, Milani P, Gade WN (2012) Biofilm formation on nanostructured titanium oxide surfaces and a micro/nanofabrication-based preventive strategy using colloidal lithography. Biofabrication 4:025001

Stout KJ, Sullivan PJ, Dong WP, Mainsah E, Luo N, Mathia T, Zahouani H (1993) The development of methods for the characterization of roughness on three dimensions. Vol. Publication no. EUR 15178 EN of the Commission of the European Communities. Scanning Probe Image Processor, SPIP, CImage Metrology A/S, Luxembourg

Tian J, Shen W (2011) Printing enzymatic reactions. Chem Commun 47:1583-1585

Van Oss CJ, Chaudhury MK, Good RJ (1987) Monopolar surfaces. Adv Colloid Interface Sci 28:35-64

Van Oss CJ, Chaudhury MK, Good RJ (1988) Interfacial Lifshitz-van Der Waals and polar interactions in macroscopic systems. Chem Rev 88:927-941

Wang J, Yiu B, Obermeyer J, Filipe CDM, Brennan JD, Pelton R (2012) Effects of temperature and relative humidity on the stability of paper-immobilized antibodies. Biomacromolecules 13:599-564

Wenzel R (1936) Resistance of solid surfaces to wetting by water. Industr Eng Chem 28:988-994

Worthington RJ, Richards JJ, Melander C (2012) Small molecule control of bacterial biofilms. Org Biomol Chem 10:7457-7474

Zmantar T, Bettaieb F, Chaieb K, Ezzili B, Mora-Ponsonnet L, Othmane A, Jaffrézic N, Bakhrouf A (2011) Atomic force microscopy and hydrodynamic characterization of the adhesion of Staphylococcus aureus to hydrophilic and hydrophobic substrata at different pH values. World J Microb Biot 27:887-896

\section{doi:10.1186/s13568-014-0032-0}

Cite this article as: Määttänen et al:: Printed paper-based arrays as substrates for biofilm formation. AMB Express 2014 4:32 